\title{
OREVER |
}

\section{Extensão em aquacultura: $O$ exemplo da produção de peixe no assentamento de reforma agrária 26 de outubro.} Extension in aquaculture: The example of fish production in agrarian
reform settlement October 26.

\begin{abstract}
Alan Figueiredo de Oliveira
alanfigueiredodeoliveira@yahoo.com.br

Mestrando em produção animal no Departamento de Zootecnia da Escola de Veterinária da UFMG.
\end{abstract}

\section{Matheus Anchieta Ramirez}

matheusarta@yahoo.com.br

Professor Adjunto do Departamento de Zootecnia da Escola de Veterinária da UFMG

\section{Márcio Fernandes Amaral}

marcio2007amaral@hotmail.com

Graduado em Aquacultura pela UFMG.

Agatha Bacelar Rabelo

agathaabr@gmail.com

Graduanda em Ciências Socioambientais pela UFMG.

Tainá Silva Brandão Lopes

tainasb118@gmail.com

Graduada em Medicina Veterinária pela UFMG.

Zélia Inês Portela Lobato

ziplobato@gmail.com

Professora Titular da Escola de Veterinária da UFMG.

Recebido em: 29/03/2019

Aprovado em: 08/10/2020
Revista do Programa de Pós-Graduação em Extensão Rural (UFV) 


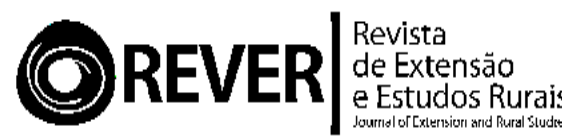

\section{RESUMO}

O trabalho foi realizado a partir das demandas da comunidade em parceria com a Escola de Veterinária da UFMG. Inicialmente foi realizado minicurso de piscicultura e reuniões comunitárias onde se buscou dar protagonismo aos produtores nas tomadas de decisão. A produção aquícola ocorreu entre 2015 a 2017. Foram realizadas 17 visitas técnicas, 13 reuniões, 2 cursos de capacitação, 6 aulas práticas e 1 evento de intercâmbio entre comunidades. Foram produzidos $1.550 \mathrm{~kg}$ de tilápia ao preço médio de venda de $\mathrm{R} \$ 8,73$. A arrecadação foi convertida em insumos para adesão de quatro novas famílias ao projeto. Os resultados demonstram a eficiência da Extensão Universitária para o aprendizado no curso de graduação em Aquacultura, fortalecimento da Agricultura familiar e a diversificação da renda para agricultores familiares a partir de pequenos investimentos e associados a práticas de mobilização social.

Palavras-Chave: Agricultura familiar; Piscicultura; Produtividade; Setor Agrário.

\begin{abstract}
The work was carried out based on the demands of the community in partnership with the Veterinary School of UFMG. Initially, a mini-course of fish farming and meetings was held to seek protagonism for producers in decision-making. Aquaculture production was carried between 2015 and 2017. There were 17 visits, 13 meetings, 2 training courses, 6 practical classes and 1 exchange event between communities. There were $1,550 \mathrm{~kg}$ of tilapia at the average sale price of $\mathrm{R} \$ 8,73$. The collection was converted into inputs for the adhesion of four new families to the project. The results demonstrate the efficiency of the University Extension for learning in Aquaculture, strengthening family farming and the income aggregation for the producer from small investments and practices of collective social mobilization.
\end{abstract}

Keywords: Family agriculture; Pisciculture; Productivity; Agrarian Sector. 


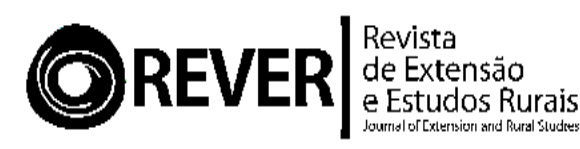

\section{Introdução}

Um dos grandes desafios deste século é garantir produção de alimentos para suprir demandas crescentes da população, principalmente fontes proteicas de origem animal. A população mundial que em 2017 foi estimada em 7,6 bilhões de pessoas, deverá ultrapassar 9,6 bilhões em 2050 (ONU, 2017). Assim, haverá aumento na necessidade de pesquisas e desenvolvimento no campo das ciências agrarias com ênfase na produção, alinhado com o uso racional dos recursos naturais com especial atenção aos recursos hídricos e a busca pela equidade social.

Aquicultura é o ramo da produção animal que vem crescendo continuamente em todo o mundo. A produção mundial de pesca e aquicultura em 1970 foi de 60 milhões de toneladas, em 2015 ultrapassou a marca dos 171 milhões de toneladas, destas, 80 milhões referentes a produção aquícola. Segundo a Organização das Nações Unidas para Alimentação e Agricultura, é previsto um crescimento de $20 \%$ na produção pesqueira até 2024 com a aquicultura ultrapassando a pesca por captura até 2023.

O crescimento do setor aquícola brasileiro vem sendo constante desde 2001, com cenário promissor para o setor no Brasil, ainda perspectivas de crescimento de até $104 \%$ até 2025 (FAO, 2016). Contudo, há vários desafios que colocam em dúvida estas projeções, como instabilidade política, ausência de agenda prepositiva para incentivo a aquicultura, dificuldades na regulamentação ambiental dos empreendimentos e um quadro geral de degradação ambiental e mudanças climáticas que podem inviabilizar o uso dos corpos hídricos.

A tilápia (Oreochromis niloticus) é uma espécie exótica, originaria da África que tem ampla distribuição produtiva no mundo, só ficando atrás da produção de Carpas como espécie de água doce mais produzida. O desempenho zootécnico satisfatório, rusticidade e tolerância a altas densidades são vantagens da produção deste peixe no Brasil, que saiu de 2 mil toneladas em 1995 para patamares acima de 219.000 toneladas em 2015 (FAO, 2016), um aumento de $1.825 \%$ em duas décadas.

Um dos desafios da Aquacultura no país é o acesso à informação, neste aspecto a Extensão Rural é essencial para o crescimento democrático da atividade, uma vez que a maioria das produções são da agricultura familiar. Sem a presença do profissional de Extensão, os produtores podem até tornarem-se reféns do mercado fornecedor, que faz assistência técnica atrelada ao fornecimento de insumos. Ademais, a Aquacultura é uma oportunidade que o setor agrário possui de reduzir as desigualdades presentes na 
agropecuária nacional, abrindo espaço para agricultores familiares, cooperativas e associações, não privilegiando apenas as grandes corporações do agronegócio.

As universidades públicas têm em sua estrutura institucional, obrigação de inserção na sociedade como parte indissociável da construção do conhecimento. Neste sentido a Extensão Universitária em Aquacultura tem que construir um caminho de vínculo com a comunidade externa, reduzir distância entre o estado e os produtores, ampliar o campo de prática e pesquisa acadêmica socialmente comprometida. A Extensão Universitária deve ser pautada em ações conjuntas com os produtores e preencher o vácuo de assistência técnica e extensão rural oficial.

O objetivo deste trabalho foi avaliar como a piscicultura atua no processo de desenvolvimento de integração comunitária, descrever a produção piscícola, avaliar a formação dos estudantes em Aquacultura com práticas de Extensão Rural Universitária em sistema produtivo e descrever a Extensão Rural Universitária na produção aquícola.

\section{Metodologia}

O projeto foi realizado no Assentamento 26 de outubro, localizado no município de Pompéu - Minas Gerais, latitude 19¹3’26” sul e longitude 4456’06 oeste, pertencente a microrregião de Três Marias e mesorregião Central de Minas, à 168 km de Belo Horizonte, capital do estado. O assentamento foi criado em 18 de janeiro de 1999 e possui área de 5.287 ha e 149 famílias assentadas.

Os problemas enfrentados pela comunidade do Assentamento 26 de outubro são os mesmos que ocorrem na maioria dos assentamentos rurais: falta de saneamento básico, atendimento médico, segurança pública, falta de infraestrutura de moradia e produção, evasão, desestímulo à produção pecuária, êxodo da juventude rural por falta de políticas voltadas para criação e a inserção dos jovens no trabalho, experiência malsucedida na formação de associação de produtores e comunidade desmobilizada.

O desenvolvimento do trabalho seguiu a metodologia comunitária participativa, onde todo o processo foi colocado em pauta em reuniões, nas quais era deliberado pelo público do assentamento perspectivas e etapas do projeto. Seguindo metodologia proposta por PRADO e RAMIREZ (2011).

O trabalho se desenvolveu por meio de mobilização comunitária e assistência técnica em Aquacultura para a produção de peixe (povoamento, medições de tamanho e peso dos peixes, cálculo das taxas de arraçoamento, limpeza de tanques, lavagem de 


\section{OREVER/:}

bolsões, homogeneização dos lotes e despesca), contabilização das despesas e receitas, provisionamento e adequação da rotina de produção aquícola as demais atividades dos produtores, como horticultura e gado leiteiro.

A proposta metodológica foi de Extensão Rural Universitária que nega a metodologia difusionista. Com proposta de assistência técnica cidadã que incentive a autonomia da comunidade. Foi utilizada uma dialética sem o abuso unilateral da retórica baseada em aspectos técnicos e que valorize saberes da comunidade em busca de intercâmbio de saberes, com a possibilidade de readequação das atividades segundo os desejos e interesses da comunidade.

\section{Resultados}

Os resultados sociais e produtivos em ações de extensão universitária são indissociáveis, bem como aqueles referentes a maior integração da universidade à sociedade e o impacto acadêmico das iniciativas.

O projeto beneficiou 40 pessoas diretamente entre produtores, comunidade acadêmica e famílias que participaram dos encontros, reuniões e cursos. Indiretamente mais de 500 pessoas foram beneficiadas pelo acesso ao pescado e pelas ações oriundas dos encontros comunitários.

Como primeiro resultado pode-se citar a formação de grupos de produtores, onde os mesmos deliberaram o local de instalação dos tanques rede. Os grupos (Caiçara e Capão da Roça) formados a partir da localização dos lotes e afinidades pessoais, passaram a determinar as ações a serem implementadas e a forma de gerência dos sistemas de produção. Coube a equipe universitária o fornecimento a cada grupo de conjunto de insumos iniciais para a produção.

O grupo Caiçara foi formado por 3 famílias, recebeu 3 tanques-rede com capacidade útil de $8 \mathrm{~m}^{3}, 2$ milheiros de tilápia, 2 bolsões e $460 \mathrm{~kg}$ de ração comercial. O grupo Capão da Roça foi formado por 2 famílias, recebeu 2 tanques-rede com capacidade útil de $8 \mathrm{~m}^{3}$, 1 milheiro de tilápia, 1 bolsão e $235 \mathrm{~kg}$ de ração.

Tabela 1. Insumos iniciais fornecidos aos grupos de produtores "Caiçara" e "Capão da Roça" para fomento ao projeto de produção de peixes em tanques rede

\begin{tabular}{lccccc}
\hline \multicolumn{1}{c}{ Grupo } & Famílias & Tanques-Rede & Alevinos & Bolsões & Ração (kg) \\
\hline Caiçara & 3 & 3 & 2 milheiros & 2 & 460 \\
Capão da Roça & 2 & 2 & 1 milheiros & 1 & 235 \\
\hline
\end{tabular}

Obs.: A capacidade útil dos tanques rede foi de $8 \mathrm{~m}^{3}$ e a densidade de 125 alevinos $/ \mathrm{m}^{3}$. 
O grupo Caiçara se localizava no maior açude do assentamento, que conta com aproximadamente 08 hectares de lâmina d'agua e profundidade média de 6 metros. Já o grupo Capão da Roça foi instalado em açude com 2 hectares e profundidade média de 4 metros. Este açude era mais degradado e apresentava baixa vazão de nascente, fatores que contribuíram para baixa qualidade de água em algumas épocas do ano.

Quanto a gestão das atividades e integração social, os grupos apresentaram propostas diferentes na condução dos trabalhos. Fato que demonstra a liberdade dada ao público para a condução das ações de extensão, bem como o protagonismo destes na implementação da iniciativa.

Os principais resultados sociais obtidos entre 2013 e 2016, foram: 13 reuniões com os grupos de produtores, 4 reuniões comunitárias, 2 cursos de capacitação (curso básico de piscicultura e curso de defumação de pescado e outros produtos da agricultura familiar) aberto a toda comunidade do assentamento, 6 aulas práticas das disciplinas: "Extensão em Aquacultura", "Limnologia Aplicada a Aquacultura" e "Sanidade de organismos aquáticos". Ainda houve a realização de evento de confraternização comunitária em comemoração ao primeiro ciclo da produção de peixe e da parceria firmada entre UFMG e comunidade, realização do primeiro encontro das comunidades rurais do município de Pompéu que contou com a presença de representantes de outras 5 comunidades, 120 participantes, oficinas, rodas de conversa e palestras.

Tabela 2. Resultados sociais quantitativos e qualitativos das atividades entre 2013 e 2016

\begin{tabular}{lc}
\multicolumn{1}{c}{ Atividades } & Quantidade \\
\hline Reuniões de grupos de produtores & 13 \\
Reuniões comunitárias & 4 \\
Cursos de capacitação & 2 \\
(Piscicultura e Defumação) & 6 \\
$\begin{array}{l}\text { Aulas práticas } \\
\text { (Extensão Rural, Limnologia e Sanidade) } \\
\text { Confraternização comunitária em } \quad \text { em }\end{array}$ & 1 \\
comemoração da parceria com a UFMG & 1 \\
I - Encontro de comunidades rurais em & \\
assentamentos de Pompéu-MG. & \\
\hline
\end{tabular}




\section{OREVER/:}

As reuniões com os produtores representaram $48 \%$ das ações programáticas e proporcionou uma maior interação entre os atores do projeto, inclusive durante as aulas práticas e demais atividades com intensa participação, sem desnível entre a equipe UFMG e produtores, caracterizando ação conjunta como método de trabalho.

O grupo Capão da Roça a partir da primeira metade do primeiro ciclo produtivo, exerceu sua autonomia, isolando suas atividades. A decisão do grupo é fruto da autogestão e autonomia, pressupostos da metodologia de extensão educativa que eleva a importância do indivíduo, independente e capaz de tomar o melhor rumo para sua vida. Sem nenhum tipo de retaliação por parte da equipe do projeto. Ao longo do tempo este grupo deixou a atividade. Motivos pelos quais apenas serão apresentados os resultados produtivos do grupo Caiçara.

O grupo Caiçara definiu mediante reuniões, o local de instalação dos tanques-rede, família responsável pelo cuidado com a produção no dia a dia e atividades que seriam realizadas em grupo. A instalação dos tanques-rede no açude obedeceu a critérios como qualidade de água, profundidade e proximidade para o produtor responsável pelo manejo dos animais.

O primeiro ciclo produtivo iniciou em janeiro de 2015 e encerrou-se em julho de 2016. Neste ciclo, os 3 tanques-rede produziram $1.550 \mathrm{~kg}$ de peixe, destes aproximadamente $100 \mathrm{~kg}$ foi utilizado na alimentação dos produtores.

Durante o ciclo produtivo, peixes com peso médio de $500 \mathrm{~g}$, foram comercializados para único comprador em despesca total de um dos tanques, o comprador foi o responsável pelo transporte dos animais vivos e os produtores foram responsáveis pela despesca.

Após a venda total do estoque de um dos tanques, o mesmo foi utilizado para a subdivisão dos peixes dos outros dois tanques. Os peixes foram classificados por tamanho, para maior homogeneização dos lotes. O restante da produção foi comercializado parceladamente na propriedade ou na feira aos sábados na sede do município de Pompéu-MG.

A estratégia de manejo alimentar dos animais era definida pelos produtores após discussão com os estudantes vinculados ao projeto. As atividades de manejo como biometrias $^{1}$ eram realizadas pela equipe do projeto juntamente com os produtores. Eram

\footnotetext{
${ }^{1}$ Manejo no qual parte dos peixes cultivados é amostrada e informações de interesse como peso e alterações patológicas são coletadas (Lima et al., 2014).
} 
pesados de 15 a 20 peixes por tanque, estimada a quantidade total de animais e calculada a quantidade de ração a ser fornecida para os animais.

O manejo alimentar adotado pelos produtores foi o fornecimento de ração farelada com 40\% PB (proteína bruta), frequência alimentar (FA) de 6 vezes/dia a taxa de $10 \%$ peso vivo (PV), para peixes de 1 até $30 \mathrm{~g}$, fase "Alevinos I". A fase "Alevinos II" compreendia peixes de 30 a 60 g, FA de 6 vezes/dia, ração de $2 \mathrm{~mm}$ e $36 \%$ PB para $10 \%$ PV. Fase "Juvenil", peixes entre 60 e 150 g, ração 4 mm, 32\% PB, 8\% PV, alimentados 4 vezes/dia. Fase "Recria" para peixes entre 150 a 400 g, ração de 6mm, 32\% PB, a 6\% PV, alimentados 3 vezes/dia. "Terminação" é a última fase produtiva, nesta etapa os animais têm acima de $400 \mathrm{~g}$, a ração comercial fornecida foi de 8 a 12 mm, 28\% PB, 3 a $1 \% \mathrm{PV}$, frequência alimentar de 2 vezes. Alimentação alternativa à base de hortaliças foi fornecida aos animais juntamente com ração comercial a partir da fase de "terminação".

Tabela 3. Manejo alimentar adotado para tilápia, da fase inicial (alevinos) até a fase final (terminação)

\begin{tabular}{lccccc}
\hline $\begin{array}{c}\text { Fase dos } \\
\text { Peixes }\end{array}$ & Peso $(\mathbf{g})$ & $\begin{array}{c}\text { Granulometria } \\
(\mathbf{m m})\end{array}$ & $\begin{array}{c}\text { Proteína } \\
\text { Bruta } \%\end{array}$ & $\begin{array}{c}\text { Peso Vivo } \\
\%\end{array}$ & $\begin{array}{c}\text { Frequência } \\
\text { Alimentar }\end{array}$ \\
\hline Alevinos I & 1 a 30 & Farelada & 40 & 10 & 6 \\
Alevinos II & 30 a 60 & 2 & 36 & 10 & 6 \\
Juvenil & 60 a 150 & 4 & 32 & 8 & 4 \\
Recria & 150 a 400 & 6 & 32 & 6 & 3 \\
Terminação & $>400$ & 8 a 12 & 28 & 3 a 1 & 2 \\
\hline
\end{tabular}

Foi gasto da farelada, para alimentação de “Alevinos I" e para transição para “Alevinos II”, 1 saco de $25 \mathrm{~kg}$, com valor de R $\$ 120,00$. Para a ração comercial $2 \mathrm{~mm}$ para a fase "Alevinos II" e transição para a fase "Juvenil", com 36\% PB, foram adquiridos 06 sacos de $25 \mathrm{~kg}$, com $\mathrm{R} \$ 90,00$ de preço unitário, e custo total $\mathrm{R} \$ 540,00$. Já para a ração comercial de 4mm e 32\% PB para fase "Juvenil", preço unitário do saco de $25 \mathrm{~kg}$ foi de $\mathrm{R} \$ 80,00$ e o custo total de 06 sacos, $\mathrm{R} \$ 480,00$. Ração comercial de $6 \mathrm{~mm}$ e $32 \%$ PB para fase de "Recria", preço unitário por saco de $25 \mathrm{~kg} \mathrm{R} \$$ 65,00, valor total de 06 sacos, R \$390,00. Ração comercial de 8mm e 28\%PB para fase de "Terminação", utilizados 10 sacos, preço unitário de $\mathrm{R} \$ 45,50$ e preço total de $\mathrm{R} \$ 455,00$. Por fim a ração comercial de $12 \mathrm{~mm}$, com $28 \%$ PB para fase de terminação, foram utilizados 05 sacos com preço 


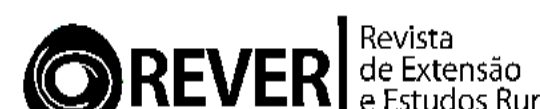 e Estudos Rurais}

unitário de $\mathrm{R} \$ 45,26$ e valor total de $\mathrm{R}$ \$226,30. Deste modo, o gasto total com ração neste ciclo produtivo foi de $\mathrm{R} \$ 2.211,30$.

Tabela 4. Quantidade, preço unitário e preço total da ração comercial utilizada pelo grupo Caiçara

\begin{tabular}{lccc}
\hline Tipo de Ração/\%PB & $\begin{array}{c}\text { Quantidade } \\
\text { (saco de 25 kg) }\end{array}$ & $\begin{array}{c}\text { Preço unitário } \\
\text { (Por saco R\$) }\end{array}$ & Total / R\$ \\
\hline Farelada 40 & 01 & 120,00 & 120,00 \\
2mm 36 & 06 & 90,00 & 540,00 \\
4mm 32 & 06 & 80,00 & 480,00 \\
6mm 32 & 06 & 65,00 & 390,00 \\
$\mathbf{8 m m} \mathbf{2 8}$ & 10 & 45,50 & 455,00 \\
12mm 28 & 05 & 45,26 & 226,30 \\
\hline Total & $\mathbf{3 4}$ & - & $\mathbf{2 . 2 1 1 , 3 0}$ \\
\hline
\end{tabular}

As despesas totais foram calculadas como conjunto de investimento em alevinos, tanques rede, corda, bolsão, tratador e ração que somaram $\mathrm{R} \$ 6.181,30$. O gasto com ração comercial foi de $\mathrm{R} \$ 2.211,30$ sendo o responsável pelo maior custo do projeto, representando 35,8\%. Porém, este valor está abaixo do custo em grandes empreendimentos que fica entre 50 e $60 \%$ (ANDRADE et al., 2005). Valor que pode ser utilizado como referência para a implantação de projetos sociais em piscicultura para grupos de produtores familiares.

O custo de 3 milheiros de alevinos foi de $\mathrm{R} \$ 450,00$ que representou 7,3\% do total das despesas. As despesas com materiais como bolsão, puçá, corda foram de $\mathrm{R} \$ 420,00$, $6,8 \%$ do total. O custo de aquisição dos 3 tanques rede foi de $\mathrm{R} \$ 2.100,00$, que representou $34 \%$ dos custos, sendo a segunda maior despesa. A despesa com o tratador foi feita ao final do ciclo, $\mathrm{R} \$ 1.000,00(16,2 \%)$. 
Tabela 5. Descrição das despesas grupo Caiçara e porcentagem representativa por item em relação a despesa total

\begin{tabular}{lcccc}
\hline \multicolumn{1}{c}{ Item } & Quantidade & Valor Unitário R\$ & Total R\$ & \% \\
\hline Alevinos & 3 milheiros & 150,00 & 450,00 & 7,3 \\
Tanques Rede & 3 unidades & 700,00 & $2.100,00$ & 34,0 \\
Corda & 1 carretel & 120,00 & 120,00 & 2 \\
Bolsão 5mm & 1 unidade & 250,00 & 250,00 & 4 \\
Puçá & 1 unidade & 50,00 & 50,00 & 0,8 \\
Tratador & 1 ciclo & - & $1.000,00$ & 16,2 \\
Ração & 34 sacos & - & $2.211,30$ & 35,8 \\
\hline Total despesas & - & - & $\mathbf{6 . 1 8 1 , 3 0}$ & $\mathbf{1 0 0}$ \\
\hline
\end{tabular}

O ciclo de produção foi estendido até a comercialização total dos peixes, finalizando em 18 meses. Desta forma, $17 \%$ da produção $(450 \mathrm{~kg})$ foi vendido a um único comprador ao preço de $\mathrm{R} \$ 5,00$ o que demonstra o papel do "atravessador" neste contexto, que paga o preço por quilo com base em cotação atacadista regional. Os $83 \%$ restante $(1.100 \mathrm{~kg})$ da produção foi comercializado na feira da cidade ou na propriedade, aumentando em mais de $100 \%$ o ganho agregado por quilo no sistema varejista chegando a ser comercializado por $\mathrm{R} \$ 12,00$.

Tabela 6. Receita da produção de tilápia em sistema de tanque rede do grupo Caiçara

\begin{tabular}{lccc}
\hline Kg de peixe & Preço Unitário $(\mathbf{R} \mathbf{\text { S }}$ & Total $(\mathbf{R} \mathbf{)}$ & \% \\
\hline $\mathbf{4 5 0}$ & 5,00 & $2.250,00$ & 17 \\
$\mathbf{1 . 1 0 0}$ & 10,00 & $11.000,00$ & 83 \\
\hline Total & - & $\mathbf{1 3 . 2 5 0 , 0 0}$ & $\mathbf{1 0 0}$ \\
\hline
\end{tabular}

Ressalta-se a grande dificuldade de inserção dos produtores no mercado, devido a questões legais, culturais, dificuldade na aquisição de insumos e de exposição dos peixes. Desta forma, qualquer projeto de implantação de produção de peixes deve ter especial atenção à comercialização do produto, pois entraves nesta fase podem levar ao fracasso a produção.

O levantamento produtivo possibilita verificar, analisar e entender a dinâmica da produção nos 18 meses. O custo por quilo de peixe produzido foi de $\mathrm{R} \$ 3,98$. A média de 


\section{OREVER}

peso dos peixes despescados foi de 717 gramas e a taxa de sobrevivência foi de 72,03\%. O índice de conversão de ração comercial (ICRC) foi de 0,550 , fato que demonstra a eficiência do sistema.

O baixo índice de ICRC é devido a extensão do tempo de estocagem com dieta composta por ração comercial e "alimentação alternativa" baseada em vegetais. Além do aproveitamento de fito e zooplâncton existente no reservatório de água, que era semi estático com razoável produção de plâncton.

O resultado financeiro do grupo Caiçara possibilitou a compra de insumos (tanques-rede, bolsões, corda, ração comercial e alevinos) para atender dois novos grupos de produtores. Decisão tomada pelos próprios produtores reunidos com ampla participação e de forma unânime. Estes insumos possibilitaram a formação de dois novos grupos de produtores, iniciar a atividade de cultivo de tilápias e a replicação posterior para outras famílias que se interessaram em participar do projeto.

Neste mesmo momento o grupo "Capão da Roça" decidiu reinvestir seu resultado econômico em novo ciclo de produção. $\mathrm{O}$ projeto realizou a orientação técnica para a compra de novos alevinos. Porém, novamente estes não se dispuseram a nenhum tipo de união nem mesmo a participarem das atividades de acompanhamento, tendo fracassado neste novo ciclo.

Tabela 8. Insumos adquiridos pelo grupo Caiçara para atendimento a 2 novos grupos de produtores e atendimento a quatro famílias

\begin{tabular}{lccc}
\hline \multicolumn{1}{c}{ Item } & Quantidade & Valor Unitário & Valor Total \\
\hline Tanques Rede 6 m & 4 & 790,00 & $3.160,00$ \\
Bolsões 5mm & 2 & 350,00 & 700,00 \\
Rolo de corda & 100 metros & 180,00 & 180,00 \\
Ração farelada 40\% PB & $25 \mathrm{Kg}$ & 4,80 & 120,00 \\
Ração 2 mm 36\%PB & 6 sacos de 25 kg & 90,00 & 540,00 \\
Alevinos de tilápia & 2 milheiros & 250,00 & 500,00 \\
\hline
\end{tabular}

Total

$-$

$5.200,00$

Importante salientar que as comunidades rurais são influenciadas por aspectos regionais, no caso da comunidade do assentamento de Reforma Agraria 26 de outubro a cultura do consumo de pescado é herdado da pesca, devido à proximidade com os rios Paraopeba e São Francisco. Esta influência manifestou-se na preferência regional por peixes nativos encontrados nestes rios como por exemplo a Curimbatá (Prochilodus 


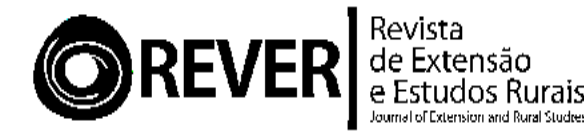

lineatus) ou Pintado (Pseudoplatystoma corruscans). Os produtores resolveram então experimentar o cultivo destas duas espécies de peixes nativos, o Curimbatá e o Piau (Leporinus freiderici) em seu próximo ciclo produtivo de forma experimental com poucos animais.

Em sua articulação ao ensino de graduação do curso de aquacultura o projeto forneceu campo para aulas práticas. Deste modo, um grupo de trabalho da disciplina de "Limnologia Aplicada a Aquacultura" em parceria com as disciplinas "Extensão em Aquacultura e "Setor Agrário e Organização Social no Brasil”, realizou trabalho prático no açude onde se localiza o sistema de produção do grupo caiçara, este trabalho contou com a participação 10 alunos e participação efetiva do produtor. $\mathrm{O}$ estudo visava o levantamento da dinâmica da vida no açude durante 24 horas, para verificar a qualidade da agua bem como mensurar os impactos gerados pela implantação do sistema de produção. Os alunos levaram equipamento necessário para análise da maioria dos parâmetros no local e coletas de água para análise mais apurada em laboratório do Instituto de Ciências Biológicas da UFMG (ICB/UFMG). Posteriormente todos os resultados foram apresentados e discutidos com os produtores. Estes mostraram boa qualidade de água, população abundante de microbiota aquática benéfica a espécies filtradoras como a tilápia que associada ao fornecimento de ração comercial possibilita um bom crescimento dos peixes. O projeto também proporcionou aos estudantes matriculados na disciplina Extensão em Aquacultura a integração entre conhecimento teórico e prático na produção de tilápia, relacionamento com produtor rural, exercício do senso crítico, comunicação, dinâmica na condução de projetos, mediação de conflitos e organização de grupo de trabalhadores.

Em sua interface a pesquisa a ação possibilitou a elaboração de trabalhos científicos, realizados a partir da experiência e que proporcionaram o aprofundamento teóricos nas situações vividas, além da participação dos alunos em congressos, simpósios e encontros acadêmicos.

Os produtores exerceram a liberdade na condução dos trabalhos, demandaram prioridades, decidiram espécies a serem cultivadas e ampliaram a produção e o número de participantes no projeto. A comunidade do assentamento ampliou sua organização social e política, atuando em várias frentes pela busca de melhorias para o assentamento. 


\section{OREVER}

\section{Discussão}

Agricultura familiar é um conjunto heterogêneo com origem nas comunidades camponesas. Possui variações e configurações ao longo do tempo e cuja definição é controversa por muitos estudiosos do tema. Diferentes perspectivas quanto as relações com o capital, tamanho da propriedade e outras relações socioeconômicas são muitas vezes utilizadas para definição contemporânea da agricultura familiar.

Dentro do universo multivariado e identitário da agricultura familiar (PRADO e RAMIREZ, 2011), a atividade aquícola tem crescimento destacado na atividade agropecuária brasileira. A despeito das grandes desigualdades regionais, a agricultura familiar representa a maior parte dos empreendimentos no meio rural, respondendo por quase $80 \%$ dos aquicultores.

De acordo com a Secretária Especial de Agricultura Familiar e Desenvolvimento Agrário, (2006) para se enquadrar nos critérios da agricultura familiar e obter acesso a linhas de crédito visando a produção aquícola, o produtor terá que explorar reservatórios hídricos com superfície de no máximo 2 ha (dois hectares) ou ocupar até $500 \mathrm{~m}^{3}$ de água em sistemas de tanque rede.

Conforme dados oficiais do censo agropecuário 2006 (IBGE, 2006), dos 18.937 estabelecimentos que declararam o tamanho do empreendimento em lâmina d'água da produção de tilápia, $79 \%$ dos produtores tinham até 2 ha de lâmina d'água, caracterizando a maioria dos produtores desta atividade.

Diante do grande crescimento da aquicultura como parte do agronegócio, é necessária análise crítica dos impactos econômicos, ambientais, sociais e de engajamento democrático nas ações de fomento, frente ao investimento destinado as grandes produções. Desta forma, a Aquacultura tem grande potencial de crescimento no Brasil, com disponibilidade hídrica, se destacando como alternativa para a superação de problemas sociais históricos no setor agrário, fortalecimento da agricultura familiar e a democratização dos espaços de produção no meio rural.

Deste modo, a Aquacultura deve ser vista como atividade de importância estratégica no desenvolvimento de comunidades rurais, na democratização do setor agrário. Para tal, é fundamental serviços de Assistência técnica e Extensão rural (ATER) com enfoque comunitário, participativo e especializada em produção aquícola.

Para tanto é relevante atentar para o fato de que a prática da Extensão Rural foi implementada no Brasil no final da década de 1940. A partir da modernização tecnológica do pós-guerra a aproximação da extensão rural com o produtor passou a obedecer a uma 
"cartilha institucionalizada". Desenhada no modelo norte americano foi trazida ao Brasil com a finalidade desenvolvimentista de vincular o produtor a financiamentos, pacotes tecnológicos, insumos e ao setor de distribuição (FONSECA, 1985), desprezando diferenças culturais e estruturais entre Brasil e Estados Unidos.

Toda dinâmica de Assistência Técnica e Extensão Rural (ATER) foi colocada em ação não considerando a realidade rural brasileira. Este processo com viés difusionista foi direcionado aos setores mais capitalizados do meio rural, ignorando os pequenos produtores, o que contribuiu com exacerbação da pobreza, concentração de terra, êxodo rural e ocupação desordenada dos centros urbanos (FONSECA et al., 2015).

Após décadas de práticas produtivistas desastrosas e desvalorização do profissional extensionista, em 2001 foi criado o Ministério do Desenvolvimento Agrário (MDA) e em 2004 instituída a Política Nacional de Assistência Técnica e Extensão Rural (PNATER). Pelo menos no papel, houve uma retomada das políticas públicas federais voltadas para a Extensão Rural, pautada na superação do modelo difusionista, porém a proposição não chegou a sua implementação definitiva.

A insuficiência da extensão em atender as demandas da Agricultura Familiar pode ser exemplificada com os dados do censo agropecuário 2006 (IBGE, 2008) onde apenas 9,5\% dos estabelecimentos nesta categoria recebiam Assistência Técnica pública e gratuita em todo Brasil.

Uma ferramenta que merece destaque no processo de expansão da aquicultura familiar é a Extensão Universitária, específica para Aquacultura. Além de assessoria técnica, esta pode contribuir para a superação do modelo produtivista. Ao trabalhar questões "humanas, com respeito as variações culturais e regionais das várias comunidades rurais espalhadas pelo Brasil. A Extensão Universitária especializada em Aquacultura com proposta inversa à metodologia pragmática é indispensável para o crescimento democrático da atividade. Uma vez que, sem ampla participação do público alvo sempre se incorrerá no erro histórico de marginalização dos agricultores familiares e o estabelecimento de uma "aristocracia" baseada em "latifúndio aquícola".

Neste contexto também não se deve esquecer que historicamente a terra foi fator de desigualdade e reprodução da pobreza no Brasil. Em 1850 a lei de terras editada pelo império só aumentou a violência, grilagem, milícias e a população andarilha despossada. Anos mais tarde, as políticas da velha república e a atuação de setores do poder público 


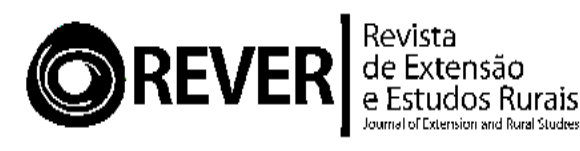

contribuíram ainda mais para o aumento do latifúndio. Porém, o quadro de desigualdade seria potencializado durante a ditadura militar com a modernização conservadora de 1965 a 1979, período de maior concentração fundiária da história. Mesmo diante do grave quadro social no campo, o tema reforma agrária só chamou a atenção do país após o surgimento das ligas camponesas e de outros movimentos sociais entre as décadas de 1940 a 1960, fenômeno que culminou com a criação do Estatuto da Terra, em 1964 e do Plano Nacional de Reforma Agrária de 1966, que não chegou a ser implementado.

A solução para a desigualdade na distribuição fundiária passa pela Reforma Agrária. Nesse ínterim, segundo dados do INCRA, em 2017 o total de assentamentos já implantados no Brasil era de 9.374 com 972.289 famílias assentadas ocupando área de 87.978.041,18 ha. Destes, apenas 2.865 assentamentos eram atendidos com ATER, representando 18,9\%. Números que apontam o descaso da assistência técnicas para estas comunidades. Em Minas Gerais existem 339 assentamentos rurais, mas apenas $26 \%$ são atendidos com ATER.

Avançar na reforma agrária é promover justiça social, democratização do acesso à terra e a fixação da população no meio rural. Todavia, esta reforma só será efetiva com investimento em políticas públicas nos assentamentos, como saneamento, energia elétrica, estradas rurais, programas de incentivo para a produção e fornecimento de ATER. Este sinergismo incrementaria a produção e fortaleceria a agricultura familiar como instituição, além de melhorar a qualidade de vida destas populações do meio rural.

Uma estratégia para diminuir o déficit de assistência técnica é a Extensão Rural Universitária. Por meio de parcerias entre prefeituras, comunidades, associações, cooperativas e Universidade, pode-se fomentar e fortalecer o atendimento a grupos socialmente excluídos como assentamentos, comunidades quilombolas, caiçaras, pescadores artesanais.

Nesta experiência de aproximação com a comunidade externa, a participação dos produtores abriu um canal de comunicação multidirecional onde vários aspectos da vida comunitária foram abordados, exercitando autonomia dos grupos locais e o intercâmbio de conhecimentos entre os envolvidos (PRADO e RAMIREZ, 2011). É ainda importante salientar o papel da mobilização no processo de amadurecimento da comunidade, que de forma democrática e coletiva atuou na busca de ampliação do movimento social que se formava.

Além disso, programas de Extensão Universitária têm por objetivo aproximar a instituição pública com a sociedade, cumprindo o artigo 207 da Constituição Federal de 
1988 (BRASIL, 1988) e as diretrizes do Fórum Nacional de Pró-Reitores de Extensão (FORPROEX, 2012), que criaram cinco pontos norteadores para esta prática: Interdisciplinaridade, Interprofissionalidade, Interação Dialógica, Indissociabilidade, promoção de impacto na formação discente e impacto na transformação social.

Segundo o censo da educação superior realizado pelo Instituto Nacional de Pesquisas Educacionais Anísio Teixeira (INEP, 2016), o Brasil possuía 296 Institutos de Ensino Superior (IES) públicos e gratuitos até o final do ano de 2016, com maior concentração destas instituições no sul e sudeste. O que abre um vasto campo para a implantação de iniciativas de Extensão Rural ligadas a Extensão Universitária, o que fortalecia a pesquisa e qualificaria a formação dos estudantes.

Os resultados demonstrados ao final do primeiro ciclo produtivo apresentaram duas perspectivas: ganhos sociais e ganhos produtivos. Em síntese, existiu um sincretismo entre as duas perspectivas, que ocorreu simultaneamente e que contribuiu para o amadurecimento das bases comunitárias. Contudo, a resposta da comunidade as atividades programadas foram bem-sucedidas, com muitas reflexões, direcionamentos, aprendizados, ensinamentos com trocas de saberes, inclusão social e participação de novas famílias.

\section{Conclusões}

O respeito e a valorização do modo de vida das comunidades rurais são passos para o reconhecimento da agricultura familiar como bem imaterial. É de suma importância para que se alcance a justiça social no campo o equilíbrio entre os interesses corporativos e culturais.

Com pouco investimento e uma metodologia de extensão rural não difusionista, voltada para o incentivo as potencialidades do produtor, alinhados a uma parceria entre comunidade e Extensão Rural Universitária, é possível a construção de cadeias produtivas para a piscicultura e do desenvolvimento das comunidades rurais em assentamentos de reforma agrária.

A replicação do modelo participativo, gerando aumento na renda do agricultor familiar, interação das comunidades e a fixação do trabalhador no campo, é possível desde que se rompa com o princípio da primazia da técnica e da perspectiva produtivista da ação. 


\section{OREVER |}

A Extensão Rural Universitária possibilita o aprendizado prático das disciplinas teorias em um ambiente real de produção com público de características especificas, solidificando sua formação técnica e humana, sendo fundamental para melhor formação dos estudantes.

A autonomia dos produtores somado as ações técnicas extensionistas em todas as etapas até a comercialização, é o resultado amplo de uma parceria entre comunidade e Extensão Rural Universitária, que retorna a sociedade o investimento público em educação na forma de trabalhos comunitários em um modelo de desenvolvimento humano.

\section{Referências bibliográficas}

ANDRADE, R. L. B.; WAGNER, L. W.; MAHL, I.; MARTINS, R. S. Custos de produção de tilápias (Oreochromis niloticus) em um modelo de propriedade da região oeste do Estado do Paraná, Brasil. Ciência Rural, v. 35, n. 1, 2005.

BRASIL. Constituição da República Federativa do Brasil. Brasília: Senado Federal, Centro Gráfico, 1988.

DA EDUCAÇÃO SUPERIOR, INEP Censo. Divulgação dos Principais Resultados. Instituto Nacional de Estudos e Pesquisas Educacionais Anísio Teixeira (INEP). Ministério da Educação (MEC), 2016.

LIMA, A. F., DA SILVA, A. P., RODRIGUES, A. P. O., PEDROZA FILHO, M. X., MACIEL, P. O., FLORES, R. M. V., BEZERRA, T. A. LIMA, A. F. Metodologia para o monitoramento de dados técnicos e econômicos em pisciculturas familiares. Embrapa Pesca e Aquicultura-Boletim de Pesquisa e Desenvolvimento (INFOTECA-E), 2014.

ORGANIZAÇÃO DAS NAÇÕES UNIDAS PARA ALIMENTAÇÃO E AGRICULTURA (FAO). El estado mundial de la pesca y acuicultura: contribuición a la seguridad alimentaria y la nutrición para todos. Roma, 2016a.

ORGANIZAÇÃO DAS NAÇÕES UNIDAS PARA ALIMENTAÇÃO E AGRICULTURA (FAO). The state of world fisheries and aquaculture: contributing to food security and nutrition for all. Roma, 2016b.

ORGANIZAÇÃO DAS NAÇÕES UNIDAS PARA ALIMENTAÇÃO E AGRICULTURA (FAO). The state of world fisheriesandaquaculture. Roma, 2012.

ORGANIZAÇÃO PARA COOPERAÇÃO E O DESENVOLVIMENTO ECONÔMICO E ORGANIZAÇÃO DAS NAÇÕES UNIDAS PARA AGRICULTURA E ALIMENTAÇÃO (OCDE-FAO). Perspectivas Agrícolas 2015-2024. 2015. Disponível em https://www.fao.org.br/download/PA20142015CB. pdf (visitado em 15 de outubro de 2018).

FONSECA, M. T. L. Extensão rural no Brasil: um projeto educativo para o capital. São Paulo: Loyola, 1985. 


\section{OREVER|}

FONSECA, W. L.; FONSECA, W. J. L.; OLIVEIRA, A. M.; VOGADO, G. M. S.; SOUZA, G. G. T. SOUZA, T. O.; SOUZA JÚNIOR, S. C.; LUZ, C. S. M. Causas e consequências do êxodo rural no nordeste brasileiro. São Paulo: Nucleus, v. 12, n. 1, p. 233-240, 2015.

FÓRUM DE PRÓ-REITORES DE EXTENSÃO DAS INSTITUIÇÕES PÚBLICAS DE EDUCAÇÃO SUPERIOR BRASILEIRAS (FORPROEX). Política Nacional de Extensão Universitária. Porto Alegre: UFRGS/Pró-Reitoria de Extensão, 2012.

INSTITUTO BRASILEIRO DE GEOGRAFIA E ESTATÍSTICA (IBGE). Censo Agropecuário 2006: Brasil, Grandes Regiões e Unidades da Federação. Rio de Janeiro, p. 1-777, 2006.

INSTITUTO NACIONAL DE COLONIZAÇÃO E REFORMA AGRÁRIA (INCRA). Incra nos Estados - Informações gerais sobre os assentamentos da Reforma Agrária. Disponível em: http://painel.incra.gov.br/sistemas/index.php. Acesso em 20 de outubro de 2018.

PRADO, E.; RAMIREZ, M.A. Agricultura familiar e extensão rural no Brasil. Belo Horizonte: FEPMVZ, 2011.

ORGANIZAÇÃO DAS NAÇÕES UNIDAS (United Nations). World Population Prospects The 2017 Revision. Key Findings and Advance Tables. New York, 2017. 